\title{
Anodizing of Aluminum Coated with Zirconium Oxide by a Sol-Gel Process I. Effect of Heat Treatment on the Formation of the Anodic Oxide Film
}

\author{
Keiji WATANABE, ${ }^{*}$ Masatoshi SAKAIRI, Hideaki TAKAHASHI, Katsumi TAKAHIRO ${ }^{\mathrm{a}}$, \\ Shinji NAGATA ${ }^{\mathrm{a}}$ and Shinji HIRAI ${ }^{\mathrm{b}}$
}

\begin{abstract}
Graduate School of Engineering, Hokkaido University, (N13, W8, Kita-Ku, Sapporo 060-8628, Japan) anstitute for Materials Research, Tohoku University, (Katahira-2, Aoba-Ku, Sendai 980-8577, Japan) ${ }^{b}$ Department of Materials Science and Engineering, Muroran Institute of Technology, (Mizumoto-cho, Muroranshi, Hokkaido 050-8585, Japan)
\end{abstract}

Received June 15, 1999 ; Accepted August 26, 1999

\begin{abstract}
Aluminum specimens were covered with zirconium oxide films by sol-gel dip coating at $T_{h}=573$ and $873 \mathrm{~K}$, and then anodized galvanostatically in a neutral borate solution. The time-variation in the anode potential during anodizing was monitored, and the structure of anodic oxide films was examined by TEM, EDX, and RBS. During anodizing of specimens coated with $\mathrm{ZrO}_{2}$ at $T_{h}=573 \mathrm{~K}$, the anode potential, $E_{a}$, increased linearly with time, $t_{a}$, and the slope of the $E_{a}$ vs. $t_{a}$ curve increased with increasing the number of sol-gel coatings. An anodic oxide film, which was composed of an inner $\mathrm{Al}_{2} \mathrm{O}_{3}$ layer and an outer $\mathrm{Al} \cdot \mathrm{Zr}$ composite oxide layer, grew at the interface between the $\mathrm{ZrO}_{2}$ layer and metal substrate during anodizing. The thickness of the inner layer increased with $t_{a}$, whereas the thickness of the outer layer showed a maximum before decreasing with $t_{a}$. Specimens coated with $\mathrm{ZrO}_{2}$ at $T_{h}=873 \mathrm{~K}$ showed $E_{a}$-jumps between 40 and $110 \mathrm{~V}$ just after the commencement of anodizing, and then a slow $E_{a}$ increase. An anodic oxide film composed of a single layer of $\mathrm{Al}_{2} \mathrm{O}_{3}$, formed beneath the $\mathrm{ZrO}_{2}$ layer during anodizing. The mechanism of the formation of anodic oxide films on aluminum coated with $\mathrm{ZrO}_{2}$ films is discussed in terms of ion transport across the anodic oxide film.
\end{abstract}

Key Words : Sol-gel Coating, Anodizing of Aluminum, Zirconium Oxide, Composite Oxide Film

\section{Introduction}

Anodic oxide film formed on aluminum has an important role as dielectric films in aluminum electrolytic capacitors. Recent development of electronics requires smaller electrolytic capacitors with higher electric capacitance. The electric capacitance, $C$, of the electrolytic capacitor is expressed by the following equation.

$$
C=\varepsilon_{0} \varepsilon S / \delta
$$

where, $\varepsilon_{0}$ is the vacuum permittivity, $\varepsilon$ the specific dielectric constant of the anodic oxide film, $S$ the surface area, and $\delta$ the film thickness. Eq. (1) indicates that $C$ is proportional to $\varepsilon$ and $S$, and inversely proportional to $\delta$. Increases in $S$, hence lead to increases in $C$, and can be achieved by electrolytic etching of the aluminum substrate before anodizing. ${ }^{1)}$ Decreases in $\delta$ can be achieved by forming anodic oxide films containing crystalline oxides, since these can sustain higher electric fields than amorphous anodic oxide films. Anodizing after hydrothermal or thermal treatments causes the formation of anodic oxide films containing $\gamma-\mathrm{Al}_{2} \mathrm{O}_{3}$, leading to a $0.8-1.0$ $\mathrm{nm} / \mathrm{V} K$-value, which is the ratio of the film thickness to the film formation potential. ${ }^{2-5)}$

Increases in $\varepsilon$ are possible by forming composite oxide films on aluminum, in which valve metal oxides like $\mathrm{TiO}_{2}, \mathrm{ZrO}_{2}$, and etc. are incorporated. In previous investigations with reference to the formation of Al-Ti composite oxide films by using a pore-filling method $^{6}$ and MOCVD/anodizing, ${ }^{7)}$ it was found that the parallel capacitance of the Al-Ti composite oxide film is $60 \%$ higher than that of barrier type anodic oxide films on aluminum.

In the present investigation, the combination of sol-gel coating with anodizing was used to form $\mathrm{Al}-\mathrm{Zr}$ composite oxide.films. Aluminum specimens were coated with $\mathrm{ZrO}_{2}$ gel film by dipping into sol solution, and then heated at $573 \mathrm{~K}$ and $873 \mathrm{~K}$. The specimens coated with $\mathrm{ZrO}_{2}$ were anodized in a neutral borate solution to obtain the Al- $\mathrm{Zr}$ composite oxide films. The structure and dielectric properties of the anodic oxide films were examined as functions of the heating temperature and the number of dipping/heating cycles in the $\mathrm{ZrO}_{2}$ coating. The results are reported in two successive papers. In the present paper, the structure and formation mechanism of the anodic oxide films are discussed, and it will be followed by a further paper describing the relationship between the film structure and its dielectric properties. 


\section{1 Specimen}

\section{Experimental Procedure}

Aluminum foil (purity: $99.99 \%$ ) was used as specimens $\left(2 \times 2 \mathrm{~cm}^{2}\right.$ with handle) after electropolishing in a perchloric acid/acetic acid mixture.

\section{2 Sol-gel coating}

Electropolished specimens were coated with $\mathrm{ZrO}_{2}$ films by sol-gel dip-coating with the procedure indicated in Fig. 1.,9) The specimens were dipped into a mixture of zirconium tetra-normal butoxide, diethylene-glycol, distilled water, and dehydrated ethanol. After withdrawn from the solution with the velocity of $3 \mathrm{~mm} / \mathrm{s}$, the specimens were dried at room temperature in air. The dried specimens were heated at $573 \mathrm{~K}$ in pure oxygen for $30 \mathrm{~min}$ to obtain the $\mathrm{ZrO}_{2}$ films. The operations described above were repeated $n$ times $(n=2 \sim 6)$, in order to change the thickness of $\mathrm{ZrO}_{2}$ films. At the final step, the specimens with $\mathrm{ZrO}_{2}$ films were heated in pure oxygen for $30 \mathrm{~min}$ at $T_{h}=$ 573 or $873 \mathrm{~K}$.

\section{3 Anodizing}

The specimens coated with $\mathrm{ZrO}_{2}$ film were anodized in $0.5 \mathrm{M}\left(\mathrm{M}=\mathrm{mol} \mathrm{dm}{ }^{-3}\right)-\mathrm{H}_{3} \mathrm{BO}_{3} / 0.05 \mathrm{M}-\mathrm{Na}_{2} \mathrm{~B}_{4} \mathrm{O}_{7}$ solution $(\mathrm{pH}=7.4)$ at $T_{a}=293 \mathrm{~K}$ with a constant current of $i_{a}=10 \mathrm{~A} / \mathrm{m}^{2}$, and the change in the anode potential (vs. $\mathrm{Ag} / \mathrm{AgCl} \mathrm{KCl}$ sat.) with time ( $E_{a}$ vs. $t_{a}$ curve) was monitored by a digital multi-meter connected with a PC system. Electropolished specimens without $\mathrm{ZrO}_{2}$ film were also anodized under the same conditions, to establish the effect of the $\mathrm{ZrO}_{2}$ films on anodic oxide film formation.

\section{4 Characterization of films}

2. 4. 1 Transmission electron microscopy (TEM) Encapsulated specimens were first trimmed, and then sliced into $40 \mathrm{~nm}$ thick sections, using an ultrami-

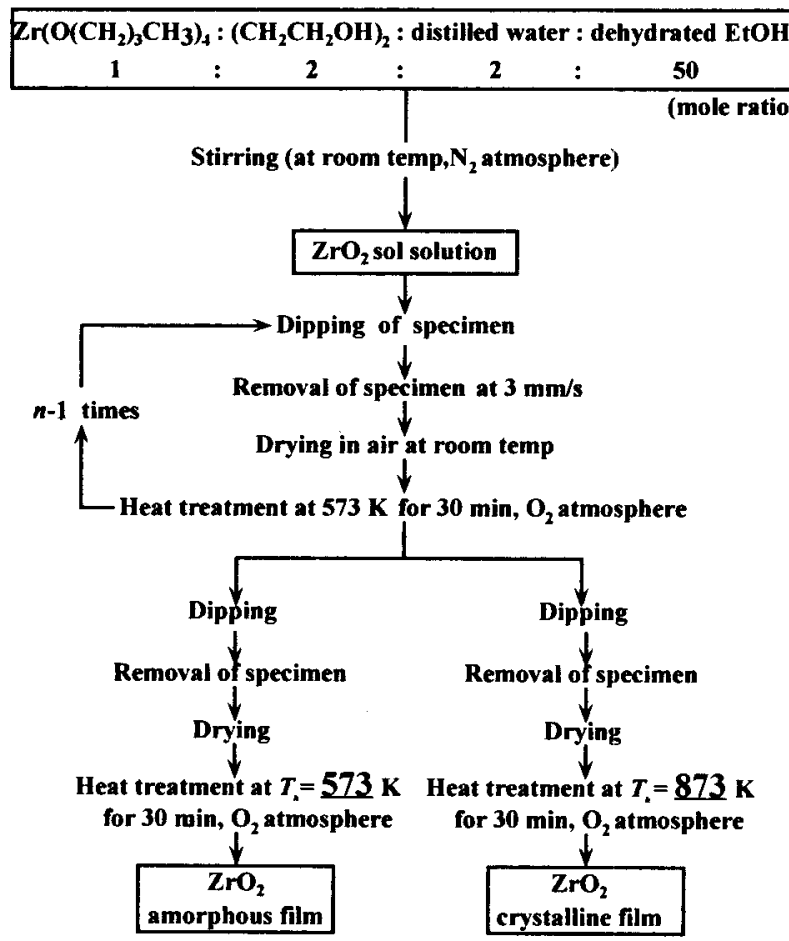

Fig. 1 Diagram of procedures of the sol-gel coating to form $\mathrm{ZrO}_{2}$ films. crotome (REICHERT-NISSEI ULTRA CUTS E) with a diamond knife (Diatome Ltd. DIATOME ULTRA). Slices of the vertical section of the specimens were then examined under a HITACHI H-700H TEM at $200 \mathrm{kV}$, and analyzed with an energy dispersive X-ray analyzer (EDX) equipped with another TEM (JEOL JEM-2000ES).

\section{4. 2 Rutherford backscattering spectroscopy (RBS)}

Anodic oxide films were analyzed by RBS(HIGH VOLTAGE ENGINEERING 1.7MV TANDETRON), using $2.0 \mathrm{MeV}$ of a $\mathrm{He}^{2+}$ ion beam supplied by a Van de Graff accelerator. The $\mathrm{He}^{2+}$ ion beam angle was normal to the specimen surface, and the detector angle was $170^{\circ}$ to the incident direction. The chemical composition of the anodic oxide films were determined, using the RUMP program. ${ }^{10}$

\section{Results}

\section{1 Formation of $\mathrm{ZrO}_{2}$ layer by sol-gel coating}

Figure 2 shows TEM images of the cross section of specimens covered with $\mathrm{ZrO}_{2}$ film. Here, the dipping/ heating cycle was repeated 4 times $(n=4)$, and heating at the final step was conducted at a) $T_{h}=573 \mathrm{~K}$ or b) $T_{h}=873 \mathrm{~K}$. Zirconium oxide layers coated at both $T_{h}$ have uniform thicknesses of about $220 \mathrm{~nm}$. Electron diffraction (ED) analysis suggests that $\mathrm{ZrO}_{2}$ coated at $T_{h}=573 \mathrm{~K}$ is amorphous, whereas at $T_{h}=873 \mathrm{~K}$ it has a fluorite-type crystal structure, consistent with the results by Takahashi et al. ${ }^{11)}$ There appear cracks perpendicular to the metal substrate in the $\mathrm{ZrO}_{2}$ layer at $T_{h}=873 \mathrm{~K}$ due to mechanical damage by the diamond knife, and this suggests poorer ductility than the $\mathrm{ZrO}_{2}$ layer at $T_{h}=573 \mathrm{~K}$.

3. 2 Formation of anodic oxide films after $\mathrm{ZrO}_{2}$ coating

Figure 3 shows $E_{a}$ vs. $t_{a}$ curves for specimens coated with $\mathrm{ZrO}_{2}$ layers at $\mathrm{n}=2 \sim 6$ and a) $T_{h}=573 \mathrm{~K}$ or b) $T_{h}=873 \mathrm{~K}$. In Fig. 3 , the $E_{a}$ vs. $t_{a}$ curve for electropolished specimens without $\mathrm{ZrO}_{2}$ is also indicated as a

$$
\begin{array}{ll}
\text { (a) } T_{h}=573 \mathrm{~K} & \text { (b) } T_{h}=873 \mathrm{~K}
\end{array}
$$

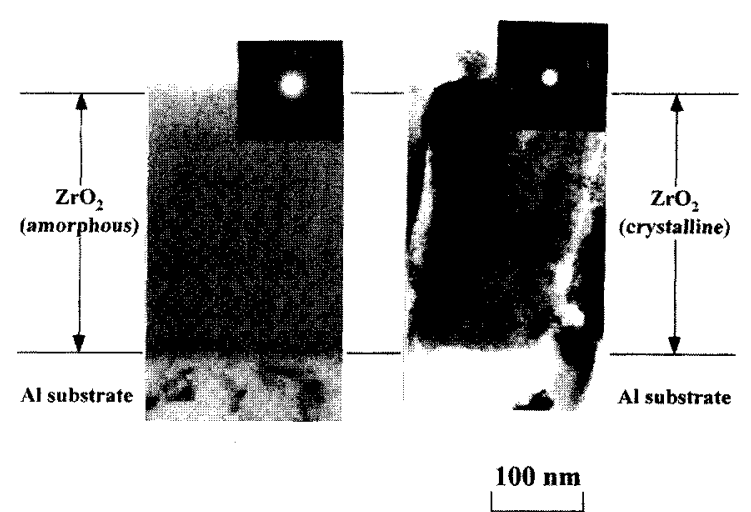

Fig. 2 Transmission electron micrographs of vertical cross sections of specimens coated with $\mathrm{ZrO}_{2}$ by sol-gel coating with $n=4$ at $T_{h}=$ a) $573 \mathrm{~K}$ or b) $873 \mathrm{~K}$. Electron diffraction patterns of the $\mathrm{ZrO}_{2}$ coated layers are shown as insets. Conditions of coating as in Fig. 1. 
solid curve. The specimen without $\mathrm{ZrO}_{2}$ shows a linear increase in $E_{a}$ with $t_{a}$. Specimens coated with $\mathrm{ZrO}_{2}$ at $T_{h}=573 \mathrm{~K}$ (see Fig. 3 -a) show a $10-15 \mathrm{~V}$ jump in $E_{a}$ just after the commencement of anodizing, and the $E_{a}$-jump does not depend on $n$. After the initial stage, $E_{a}$ increases linearly with $t_{a}$. The slope of $E_{a}$ vs. $t_{a}$ curves for $\mathrm{ZrO}_{2}$-coated specimens is much steeper than that without a $\mathrm{ZrO}_{2}$ layer, and it increases with the number of dipping/heating cycles, $n$.

Specimens coated at $T_{h}=873 \mathrm{~K}$ (see Fig. 3-b) show a 40-110 V-jump in $E_{a}$ just after the commencement of anodizing, and the $E_{a}$-jump increases with $n$. After an initial transient period, $E_{a}$ increases slowly with $t_{a}$, and then the rate of increase in $E_{\alpha}$ reaches a steady value, similar to that of the specimens without $\mathrm{ZrO}_{2}$. The slow increase in $E_{a}$ at the early stage was accompanied by gas evolution.

3. 3 Structure of anodic oxide films formed after $\mathrm{ZrO}_{2}$ coating at $T_{h}=573 \mathrm{~K}$

Figure 4 shows TEM images of cross sections of specimens anodized up to a) $E_{a}=200 \mathrm{~V}$ and b) $E_{a}=400$ $\mathrm{V}$ after $\mathrm{ZrO}_{2}$ coating with $n=4$ at $T_{h}=573 \mathrm{~K}$. The anodized specimens show two layers between the $\mathrm{ZrO}_{2}$ layer and the metal substrate: an outer dark layer and an inner light-gray layer. The outer layer is much thicker at $E_{a}=200 \mathrm{~V}$ than at $E_{a}=400 \mathrm{~V}$, whereas the inner layer is much thinner at $E_{a}=200 \mathrm{~V}$ than at $E_{a}=400 \mathrm{~V}$.

Figure 5 shows a) the RBS spectrum obtained for specimens anodized up to $E_{a}=400 \mathrm{~V}$ after $\mathrm{ZrO}_{2}$ coating with $n=4$ at $T_{h}=573 \mathrm{~K}$, and b) the concentration depth-profile of $\mathrm{Zr}, \mathrm{Al}$, and $\mathrm{O}$, derived from the RBS

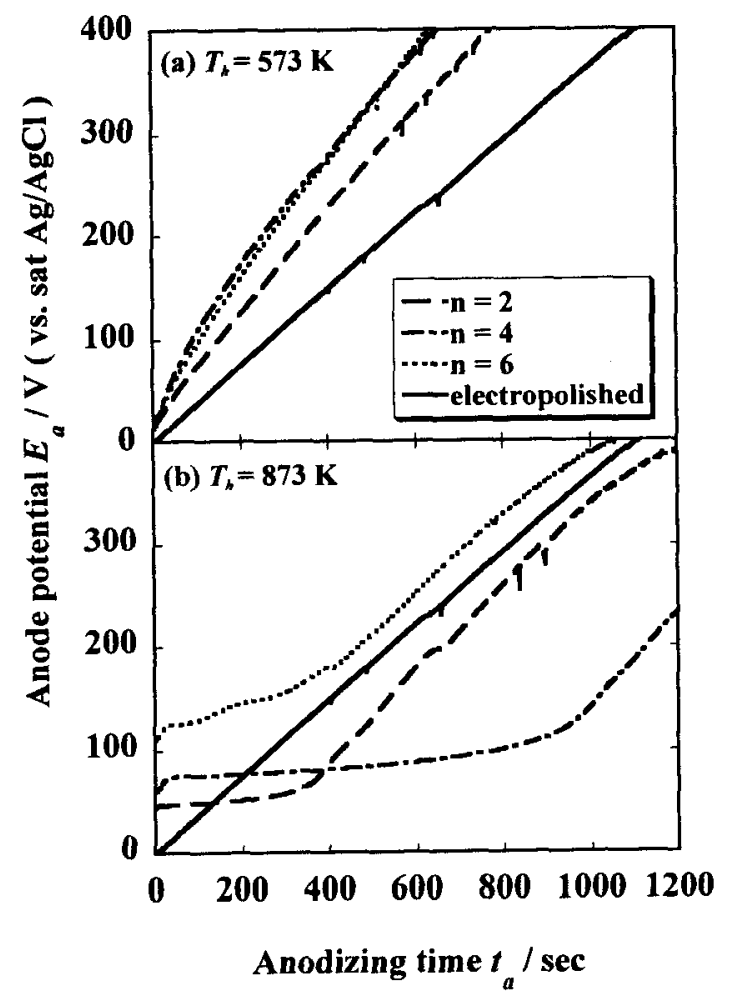

Fig. 3 Change in anode potential, $E_{a}$ with time, $t_{a}$, during anodizing in $0.5 \mathrm{M}-\mathrm{H}_{3} \mathrm{BO}_{3} / 0.05 \mathrm{M}-\mathrm{Na}_{2} \mathrm{~B}_{4} \mathrm{O}_{7}$ solution at 293 $\mathrm{K}$ and $10 \mathrm{~A} / \mathrm{m}^{2}$, obtained for specimens coated with $\mathrm{ZrO}_{2}$ at $T_{h}=$ a) $573 \mathrm{~K}$ or b) $873 \mathrm{~K}$. spectrum using the RUMP program. ${ }^{10)}$ Figure 5-b suggests that the outer dark layer in Fig. 4 consists of an $\mathrm{Al}-\mathrm{Zr}$ composite oxide layer, and that the inner light-gray layer consists of an alumina layer. Hafnium included in the $\mathrm{ZrO}_{2}$ layer comes from impurities in the $\mathrm{Zr}$-alkoxide. The EDX analysis of the $\mathrm{Al}-\mathrm{Zr}$ composite oxide layer estimated the Al concentration to be about $15 \%$.

Figure 6 shows the change in the thicknesses of the outer $\mathrm{Al}-\mathrm{Zr}$ composite oxide layer, $\delta_{\mathrm{c}}$ (Fig. 6-a), and of the inner alumina layer, $\delta_{a}$ (Fig.6-b), with anodizing time, $t_{a}$, after $\mathrm{ZrO}_{2}$ coating with different $n$ at
(a) $E_{a}=200 \mathrm{~V}$
(b) $E_{\alpha}=400 \mathrm{~V}$

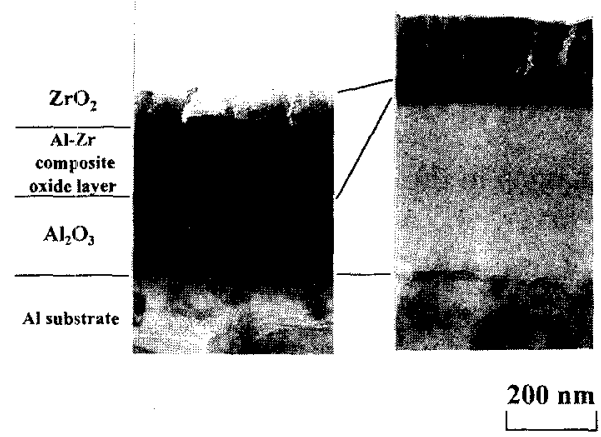

Fig. 4 Transmission electron micrographs of cross sections of specimens anodized up to $E_{a}=$ (a) $200 \mathrm{~V}$ and (b) 400 $\mathrm{V}$ after $\mathrm{ZrO}_{2}$ coating with $n=4$ at $T_{h}=573 \mathrm{~K}$. Conditions of coating as in Fig. 1, and anodizing as in Fig. 3.

(a)

(b)
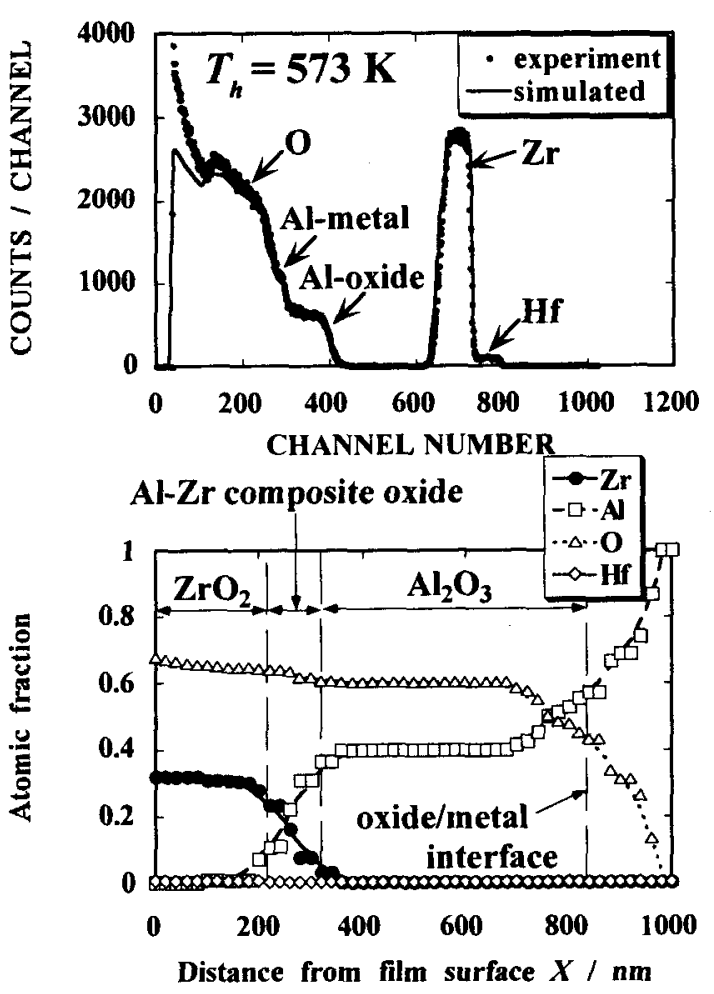

Fig. 5 a) RBS spectrum and b) concentration profiles of $\mathrm{Zr}, \mathrm{Al}, \mathrm{O}$, and $\mathrm{Hf}$ in depth for specimens anodized up to $E_{a}=400 \mathrm{~V}$ after $\mathrm{ZrO}_{2}$ coating with $n=4$ and $T_{n}=573 \mathrm{~K}$. Conditions of anodizing as in Fig. 3. 


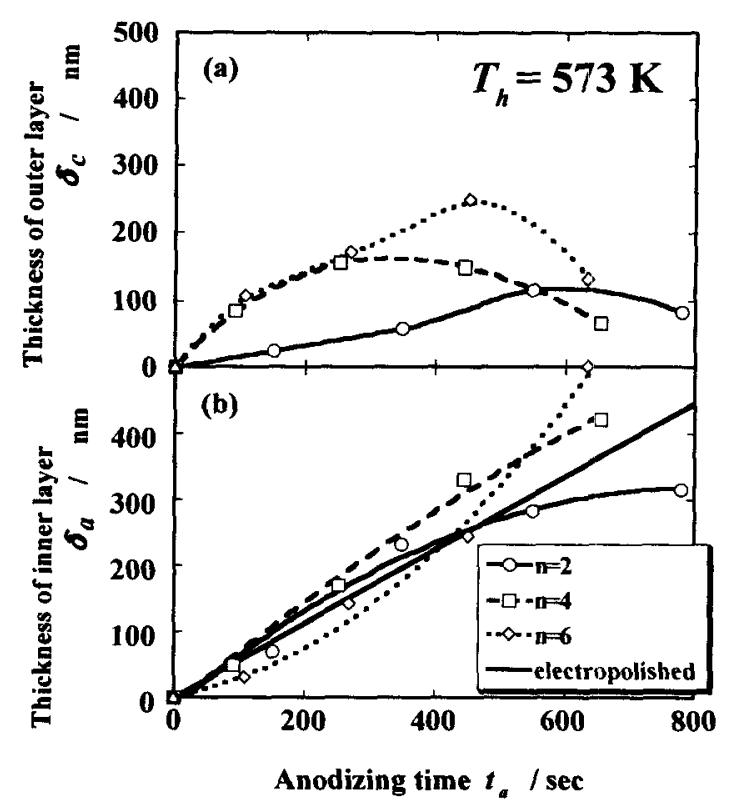

Fig. 6 Changes in the thickness of the outer layer, $\delta_{c}$, and the inner layer, $\delta_{a}$, with $t_{a}$, for specimens after $\mathrm{ZrO}_{2}$ coating at $T_{h}=573 \mathrm{~K}$. Conditions of anodizing as in Fig. 3.

$T_{h}=573 \mathrm{~K}$. The change in the thickness of anodic oxide films formed on aluminum without $\mathrm{ZrO}_{2}$ with $t_{a}$ is shown as a solid curve in Fig. 6 . The fillm thickness of the specimen without $\mathrm{ZrO}_{2}$ shows a linear increase with $t_{a}$, but the change in $\delta_{a}$ with $t_{a}$ is complicated and different for different $n$ values. At the initial stage, all the $\delta_{a}$ vs. $t_{a}$ curves of $\mathrm{ZrO}_{2}$-coated specimens show a slope similar to that of the specimen without $\mathrm{ZrO}_{2}$. In the later stage, the slope becomes flatter for specimens with $n=2$, while the slope becomes steeper for specimens with $n=4$ and 6 . The tendency towards upward deviation in the slope becomes more remarkable with increasing $n$.

The thickness of the outer Al- $\mathrm{Zr}$ composite oxide layer, $\delta_{c}$, on all the specimens coated with $\mathrm{ZrO}_{2}$ at $T_{h}=573 \mathrm{~K}$ shows an increase in the initial stage and then decreases after a maximum. The maximum $\delta_{c}$ value increases with increasing $n$.

3. 4 Structure of anodic oxide films formed after $\mathrm{ZrO}_{2}$ coating at $T_{h}=873 \mathrm{~K}$

Figure 7 shows TEM images of cross sections of specimens anodized up to a) $E_{a}=200 \mathrm{~V}$ and b) $E_{a}=400$ $\mathrm{V}$ after $\mathrm{ZrO}_{2}$ coating with $n=4$ at $T_{h}=873 \mathrm{~K}$. It can be seen from Fig. 7 that an oxide layer grows at the interface between the $\mathrm{ZrO}_{2}$ layer and the metal substrate during anodizing, and that crystalline oxide is formed at the middle part of the oxide layer. The EDX and ED analyses suggested that the oxide layer is composed of $\mathrm{Al}_{2} \mathrm{O}_{3}$, and that the crystalline oxide is $\gamma-\mathrm{Al}_{2} \mathrm{O}_{3}$. Figure 8 shows the change in the thickness of the alumina layer, $\delta_{a}$, with anodizing time, $t_{a}$, after $\mathrm{ZrO}_{2}$ coating with different $n$ at $T_{h}=873 \mathrm{~K}$. The $\delta_{a}$ increases slowly with time, $t_{a}$, in the initial stage of anodizing, and then increases at a high rate in the later stage. The rate of increase in $\delta_{a}$ at the initial period increases with increasing $n$, whereas the rate
(a) $E_{a}=\mathbf{2 0 0 \mathrm { V }}$
(b) $E_{a}=400 \mathrm{~V}$

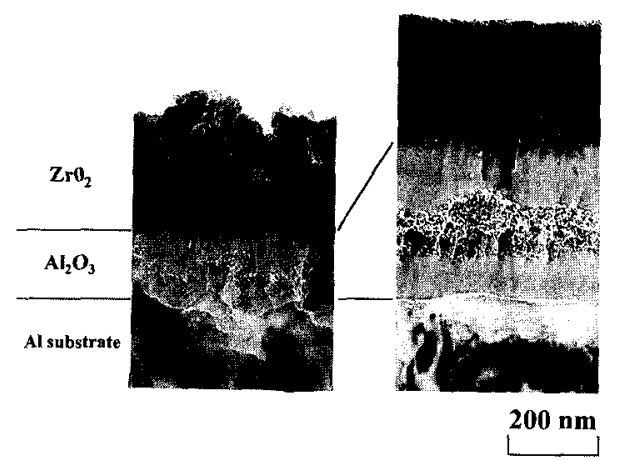

Fig. 7 Transmission electron micrographs of vertical sections of specimens anodized up to $E_{a}=$ a) $200 \mathrm{~V}$ and b) $400 \mathrm{~V}$ after $\mathrm{ZrO}_{2}$ coating at $n=4$ and $T_{h}=873 \mathrm{~K}$. Conditions of coating as in Fig. 1, and anodizing as in Fig. 3.

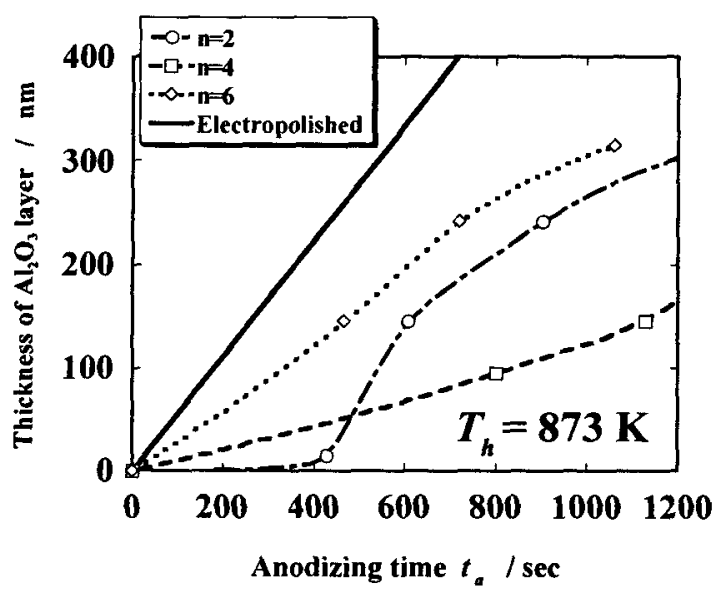

Fig. 8 Changes in the thickness of the $\mathrm{Al}_{2} \mathrm{O}_{3}$ layer with anodizing time, $t_{a}$, obtained for specimens after $\mathrm{ZrO}_{2}$ coating with $T_{h}=873 \mathrm{~K}$. Conditions of anodizing as in Fig. 3.

of increase in $\delta_{a}$ at the later stage does not depend on $n$.

\section{Discussion}

4. 1 Growth mechanism of anodic oxide films after $\mathrm{ZrO}_{2}$ coating at $T_{h}=\mathbf{5 7 3} \mathrm{K}$

Figure 9-a shows a schematic model of the formation of the anodic oxide film during anodizing after $\mathrm{ZrO}_{2}$ coating at $T_{h}=573 \mathrm{~K}$. The zirconium oxide layer is considered to have a network structure of micropores and cracks, which are formed by the evaporation of organic compounds during heating of the sol precursor film. The micro-pore network structure may be reduced in the inner parts of the $\mathrm{ZrO}_{2}$ layer by the repetition of the dipping/heating, since the repetition would allow the sol solution to penetrate into micro cracks. During heat treatment, a thin thermal aluminum oxide film may also be formed at the interface between the $\mathrm{ZrO}_{2}$ layer and metal substrate .)

When the specimen coated by $\mathrm{ZrO}_{2}$ at $T_{h}=573 \mathrm{~K}$ is immersed in anodizing solution, water and electrolyte could penetrate into the micro-pore network in $\mathrm{ZrO}_{2}$, 

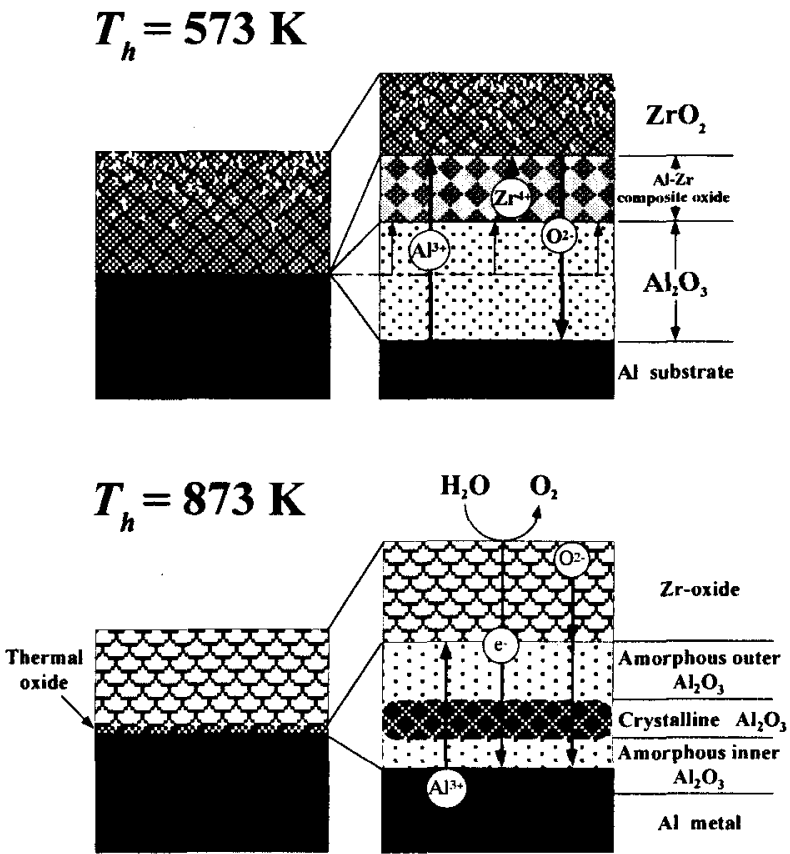

Fig. 9 Schematic illustrations of the formation of anodic oxide films after $\mathrm{ZrO}_{2}$ coating at a) $T_{h}=573 \mathrm{~K}$ and at b) $T_{h}=873 \mathrm{~K}$.

so that the $\mathrm{ZrO}_{2}$ layer is not able to sustain an electric field. The small jump in $E_{a}$ just after the commencement of anodizing (See Fig. 3-a) may be due to the aluminum thermal oxide layer rather than $\mathrm{ZrO}_{2}$ layers. This may be understood by the fact that the jump in $E_{a}$ does not depend on $n$. A similar jump in $E_{a}$ has been observed in anodizing aluminum after heat treatment in air .4)

During anodizing after $\mathrm{ZrO}_{2}$ coating, $\mathrm{O}^{2-}$ ions dissociated from water at the bottom of the $\mathrm{ZrO}_{2}$ layer transport inwards across the anodic oxide film to form pure aluminum oxide at the interface between the inner $\mathrm{Al}_{2} \mathrm{O}_{3}$ layer and metal substrate. The outward transport of $\mathrm{Al}^{3+}$ ions may allow the formation of a composite oxide layer by filling the micro pores with $\mathrm{Al}_{2} \mathrm{O}_{3}$ at the interface between the outer composite oxide layer and the $\mathrm{ZrO}_{2}$ layer. In addition to the formation of oxide at the two interfaces, a conversion of the composite oxide to $\mathrm{Al}_{2} \mathrm{O}_{3}$ may occur at the interface between the outer and inner layers, due to the outward transport of $\mathrm{Zr}^{4+}$ or $\mathrm{ZrO}^{2+}$ ions under the electric field across the composite oxide layer.

Assuming that the transport number of $\mathrm{Al}^{3+}$ and $\mathrm{O}^{2-}$ ions remains constant during anodizing, the growth mechanism of the outer and inner layers can be explained as follows. The downward deviation in the $\delta_{a}$ vs. $t_{a}$ curve for the specimen with $n=2$ from that for the specimen without $\mathrm{ZrO}_{2}$ coating may be concerned with the micro-pore network, and with the conversion rate of composite oxide to $\mathrm{Al}_{2} \mathrm{O}_{3}$. The $n=2$ specimen may be considered to have the most developed micropore network structure especially at regions near the surface, and to have the slowest conversion, and this causes the downward deviation. With $n \geqq 4$, the micropore network structure is reduced and the conversion becomes faster as $n$ increases, causing more upward deviation in the $\delta_{a}$ vs. $t_{a}$ curve with the larger $n$.

The net rate of increase in $\delta_{c}$ is obtained by subtracting the conversion rate of the composite oxide layer at the interface between the inner and outer layers from the formation rate of the composite oxide layer at the interface between the outer and $\mathrm{ZrO}_{2}$ layers. The fact that $\delta_{\mathrm{c}}$ shows a maximum at the intermediate period of anodizing may be explained by a decrease in the formation rate of the composite oxide layer with $t_{a}$, due to a larger porosity at the outer region of the $\mathrm{ZrO}_{2}$ layer.

4. 2 Growth mechanism of anodic oxide films after $\mathrm{ZrO}_{2}$ coating at $T_{h}=873 \mathrm{~K}$

The structure of the $\mathrm{ZrO}_{2}$ layers formed at $T_{h}=873$ $\mathrm{K}$ is very different from that formed at $T_{h}=573 \mathrm{~K}$, showing fluorite-type crystals and no network of micro cracks. This causes the anodic oxide film to grow in a different way after the $\mathrm{ZrO}_{2}$ coating.

Figure 9-b shows a schematic model of the anodic oxide film growth after $\mathrm{ZrO}_{2}$ coating at $T_{h}=873 \mathrm{~K}$. Here, a dense crystalline $\mathrm{ZrO}_{2}$ layer blocks the solution penetration, and it can sustain an anode potential, $E_{a}$. This may explain a relatively large jump in $E_{a}, 40-110 \mathrm{~V}$, at the very initial stage of anodizing (Fig. 2-b), and $n$ dependence of the $E_{a}$-jump. The slow increase in $E_{a}$ after the jump is due to $\mathrm{O}_{2}$ evolution, and this is attributed to the electron conductivity of the $\mathrm{ZrO}_{2}$. In addition to $\mathrm{O}_{2}$ evolution, $\mathrm{O}^{2-}$ ions are formed by water dissociation and transport inwards across the $\mathrm{ZrO}_{2}$ layer to form an $\mathrm{Al}_{2} \mathrm{O}_{3}$ layer at the interface between the metal substrate and $\mathrm{ZrO}_{2}$. After the $\mathrm{Al}_{2} \mathrm{O}_{3}$ layer grows to a certain thickness, $\mathrm{O}_{2}$ evolution slows down and the formation of $\mathrm{Al}_{2} \mathrm{O}_{3}$ becomes predominant.

The $\mathrm{O}^{2-}$ ions reaching the interface between the $\mathrm{ZrO}_{2}$ and $\mathrm{Al}_{2} \mathrm{O}_{3}$ layers could either react with $\mathrm{Al}^{3+}$ ions to form $\mathrm{Al}_{2} \mathrm{O}_{3}$ there, or could transport further inwards across the $\mathrm{Al}_{2} \mathrm{O}_{3}$ layer to form $\mathrm{Al}_{2} \mathrm{O}_{3}$ at the interface between the $\mathrm{Al}_{2} \mathrm{O}_{3}$ layer and metal substrate. The formation of crystalline oxide layers at the middle part of the $\mathrm{Al}_{2} \mathrm{O}_{3}$ layer may be due to the crystallization of amorphous oxide under a high electric field, and thermal $\mathrm{Al}_{2} \mathrm{O}_{3}$ formed at $\mathrm{ZrO}_{2}$ may act as crystal seeds in the crystallization of amorphous oxide. $^{5)}$

\section{Conclusion}

The formation of $\mathrm{Al}-\mathrm{Zr}$ composite oxide films on aluminum was attempted by sol-gel coating and subsequent anodizing, and the following conclusions may be drawn.

1. The zirconium oxide layer coated on aluminum substrates by sol-gel coating consists of an amorphous oxide at a heating temperature, $T_{h}=573 \mathrm{~K}$, and it is fluorite-type crystalline oxide at $T_{h}=873 \mathrm{~K}$.

2. Galvanostatic anodizing of aluminum coated with $\mathrm{ZrO}_{2}$ at $T_{h}=573 \mathrm{~K}$ leads to the formation of oxide films consisting of an outer $\mathrm{Al}-\mathrm{Zr}$ composite oxide layer and an inner $\mathrm{Al}_{2} \mathrm{O}_{3}$ layer at the interface 
between the $\mathrm{ZrO}_{2}$ layer and metal substrate. The thickness of the inner layer, $\delta_{a}$, increases with time, and the rate of increase in $\delta_{a}$ increases with increasing number of dipping/heating cycles, $n$. The thickness of the outer layer, $\delta_{c}$, initially increases with time, and then decreases after a maximum. This tendency is more pronounced for specimens with larger $n$-values.

3. Galvanostasic anodizing of aluminum coated with $\mathrm{ZrO}_{2}$ at $T_{h}=873 \mathrm{~K}$ leads to the formation of an $\mathrm{Al}_{2} \mathrm{O}_{3}$ layer at the interface between the $\mathrm{ZrO}_{2}$ and metal substrate. The $\mathrm{Al}_{2} \mathrm{O}_{3}$ layer includes an $\gamma-\mathrm{Al}_{2} \mathrm{O}_{3}$ layer at the middle part.

\section{Acknowledgments}

The authors wish to thank K. Nishinaka, K. Dohjun, and R. Hasegawa of Muroran Institute of Technology for experimental assistance on the sol-gel coating. The work was financially supported by the Light Metal Education Foundation of Japan, and the Ministry of Education, Science, Sports and Culture, Japan with a Grand-in-Aid for Scientific Research on Priority Areas for "Electrochemistry of Ordered Interfaces"(No. 10131204). A part of this work was carried out under the Visiting Researcher's Program of the Institute for Materials Research, Tohoku University.

\section{References}

1) For example, R. S. Alwitt, H. Uchi, T. R. Beck, and R. C. Alkire, J. Electrochem. Soc., 144, 13 (1997).

2) H. Takahashi, Y. Umehara, T. Miyamoto, N. Fujimoto, and M. Nagayama, J. Surf Finish. Soc. Jpn., 38, 67 (1987).

3) H. Takahashi, Y. Umehara, R. Furuichi, and M. Nagayama, J. Surf Finish. Soc. Jpn., 40, 590 (1989).

4) H. Takahashi, C. Ikegami, M. Seo, and R. Furuichi, J. Electron. Microsc., 40, 101 (1991).

5) H. Takahashi, M. Dairaku, and M. Seo, J. Surf Finish. Soc. Jpn., 45, 810 (1994).

6) M. Shikanai, M. Sakairi, H. Takahashi, M. Seo, K. Takahiro, S. Nagata, and S. Yamaguchi, J. Electrochem. Soc., 144, 2756 (1997).

7) H. Takahashi, H. Kamada, M. Sakairi, K. Takahiro, S. Nagata, and S. Yamaguchi, Meeting Abstracts of the 193rd meeting of the Electrochemical Society, Inc., No. 207 (1998).

8) S. Hirai, S. Aizawa, K. Shimakage, and K. Wada, $J$. Japan Inst. Metals., 59, 547 (1995).

9) S. Hirai, K. Shimakage, S. Aizawa, and K. Wada, $J$. Am. Ceram. Soc., 81, 3087 (1998).

10) L. R. Doolittle, Nucl. Inst. Meth., B15, 227 (1986).

11) Y. Takahashi, K. Niwa, K. Kobayashi, and M. Matsuki, Yogyo-Kyokai-Shi., 95, 942 (1987). 